M. Monastyrov, T. Prikhna, B. Halbedel, G. Kochetov, F.D.S. Marquis, A.G. Mamalis and O. Prysiazhna

\title{
Electroerosion dispersion, sorption and coagulation for complex water purification: Electroerosion waste recycling and manufacturing of metal, oxide and alloy nanopowders
}

ABSTRACT. The application of EEDSC-electroerosion dispersion, sorption and coagulation (using in situ dispersion in plasma of aluminium or iron) -allowed efficient water purification from heavy metal ions and radioactive alkali ions (of $\mathrm{Fe}, \mathrm{Cr}, \mathrm{Cu}, \mathrm{Mo}, \mathrm{Zn}, \mathrm{Co}, \mathrm{Ni}, \mathrm{Cd}, \mathrm{Mn}, \mathrm{As}, \mathrm{Sn}$, $\mathrm{Pb}, \mathrm{Al}, \mathrm{Ba}, \mathrm{Co}, \mathrm{Cs}$ and $\mathrm{Sr}$ ) as well as from organic contamination. Intensive ozonization should be applied because of intensive foam formation as a result of complex electrohydrodynamic effects during removal of the "heavy" organic contaminants (such as from liquid waste from landfills) during EEDSC. The method of electroerosion dispersion is very effective for the production of nano and submicron powders $(5 \mathrm{~nm}-3 \mu \mathrm{m})$ of metals, oxides, nitrides and carbides as well as for recycling of any conductive materials such as cemented carbides, alloys of heavy metals, metallic waste products etc. The iron oxide polyvalent magnetic nanoparticles produced by electroerosion dispersion attract considerable interest in many fields of research and application. They have high potential for applications in the field of biomedical sciences (diagnostics and therapy), ferrofluids, catalysis, coloured pigments, high-density magnetic recording, printer toners, Li-ion batteries, wastewater treatment and absorption of electromagnetic waves.

Keywords: aluminium oxides, electroerosion dispersion, iron oxides, nanopowders, sorption and coagulation, water purification

Nanotechnology Perceptions 15 (2019) 48-57

doi: 10.4024/N24MO18A.ntp.15.01 